\title{
Comparison of left and right ventricular adaptation in endurance-trained male athletes
}

\author{
Zs Major ${ }^{1}$, E Csajági², Zs Kneffel ${ }^{3}$, T Kováts ${ }^{4}$, I Szauder ${ }^{5}$, Z Sidó ${ }^{6}$, G Pavlik ${ }^{2}$ \\ ${ }^{1}$ Department of Physical Education and Sport Scienses, College of Nyíregyháza, Nyíregyháza, Hungary \\ ${ }^{2}$ Department of Health Sciences and Sport Medicine, University of Physical Education, Budapest, Hungary \\ ${ }^{3}$ Sport Science Program, Qatar University, Doha, Qatar \\ ${ }^{4}$ Heart Centre, Semmelweis University, Budapest, Hungary \\ ${ }^{5}$ Cardiologic Diagnostic Centre, Budapest, Hungary \\ ${ }^{6}$ National Institute for Sport Medicine, Budapest, Hungary
}

Received: January 7, 2014

Accepted after revision: July 31, 2014

\begin{abstract}
Characteristics of the athlete's heart have been investigated mostly in the left ventricle (LV); reports referring to the right ventricle (RV) have only appeared recently. The aim of the present study was to compare the training effects on RV and LV in elite male endurance athletes. To this end, echocardiography was conducted in 52 elite endurance athletes (A) and in 25 non-athletes (NA). Differences between A and NA in the morphology was more marked in the RV (body-size-matched (rel.)) long axis diastolic diameter (RVLADd): $63.4 \pm 6.3$ vs. $56.4 \pm 6.3$; rel. short axis diastolic diameter (RVSADd): $27.3 \pm 3.6$ vs. $23.6 \pm 2.7 \mathrm{~mm} / \mathrm{m}$, RV diastolic area $28 \pm 5.0$ vs. $21.3 \pm 4.3 \mathrm{~cm}^{2}$ in all cases, $p<0.001$ ) than in the LV (rel. LVLADd: $63.8 \mathrm{~mm} / \mathrm{m} \pm 5.6$ vs. $60.7 \mathrm{~mm} / \mathrm{m} \pm 6.6, p<0.05$, rel.LVSADd 37.8 \pm 3.1 vs. $35.3 \pm 2.4$, no difference). In the athletes ratios of peak early to late diastolic filling velocity $(2.07 \pm 0.51$ vs. $1.75 \pm 0.36, p<0.01)$, the TDI-determined $\mathrm{E}^{\prime} / \mathrm{A}^{\prime}$ ratio in the septal $(1.89 \pm 0.55$ vs. $1.62 \pm 0.55, p<0.05)$ and lateral $(2.62 \pm 0.72$, vs. $2.18 \pm 0.87, p<0.001)$ walls were significantly higher than in NA only in the LV. Results indicate that in male endurance athletes morphologic adaptation is similar or slightly stronger in the RV than in the $\mathrm{LV}$, functional adaptation seems to be stronger in the LV.
\end{abstract}

Keywords: transthoracic echocardiography, left and right ventricle, cardiac enlargement, systolic and diastolic function, elite athletes

The athlete's heart has been investigated extensively in the past decades, and most of this research has been concerned with the $\operatorname{LV}(1,3,16,19)$. Because of some methodological difficulties, such as the crescent, frequently triangular shape, the large number of trabeculation in its wall and the hinge line of the septal leaflet of the TV, RV has not been frequently investigated. There are, however, differences in some basic data of the RV and LV structure and function in healthy sedentary people (9).

Due to the improved technical possibilities, investigations of the RV have become widespread in the last decade, and several studies have referred to the adaptation of RV to regular physical exercise either by means of echocardiography $(5,6,7,8,13,24)$ or MRI (17, 21, 22). RV has, however, a special importance: its morphological and functional defects, especially arrhytmogenic RV cardiomyopathy or dysplasia, can lead to cardiac arrest or sudden cardiac death (4).

Corresponding author: Gábor Pavlik

Department of Health Sciences and Sport Medicine, University of Physical Education

Alkotás u. 44, H-1123 Budapest, Hungary

Phones: +36-1-487-9285,+36-30-350-6887; E-mail: pavlik@tf.hu 
In our previous reviews, which refer mostly to the LV, athletic characteristics of the heart were divided into morphologic, functional and regulatory areas $(14,15)$. In the present study, we examined characteristics of the RV in a similar way. The regulatory parameters mean the modified autonomous control of the heart, in the main manifestations of it (lower HR, cardiac output) no differences between the two ventricles were expected.

Petersen et al. (18) observed a greater increase in LV than RV muscle mass in young endurance-trained males. In several papers $(5,6,12,22)$ and reviews $(2,3)$ a similar increase in the RV and LV was reported. Several authors $(11,23,24)$ have reported a significantly greater increase in the RV than the LV in endurance athletes.

The RV function of the athlete's heart can be characterised by several parameters. Systolic function can be characterised by the fractional area change (RVFAC) or by Tricuspid Annular Plane Systolic Excursion (TAPSE). Similarly to the LV, tricuspid E/A represents RV diastolic function, and from the TDI parameters $S$ ' indicates systolic, with E'/A' indicating diastolic function.

In several studies, no difference was found between endurance athletes and non-athletes in the $\mathrm{LV}$ ejection fraction $(3,15,19)$. The RV ejection fraction is a rarely measured index, but RVFAC is very similar to RV ejection fraction and is used to estimate RV systolic function. D'Andrea et al. (6) did not find a difference in this parameter between power and endurance athletes and sedentary subjects. Some authors found, however, smaller RV changes in athletes than in non-athletes $(11,20)$.

In the TAPSE, Teske et al. (24) found higher values only in elite endurance athletes compared to the controls, while no difference was found by D'Andrea et al. (6) between either power or endurance athletes and non-athletes.

\begin{tabular}{|c|c|c|c|}
\hline \multicolumn{4}{|c|}{ Abbreviations } \\
\hline A & $\begin{array}{l}\text { - peak flow velocity of the late (atrial) phase } \\
\text { of diastolic filling }\end{array}$ & LVSADd & $\begin{array}{l}\text { - left ventricular short axis internal end- } \\
\text { systolic diameter }\end{array}$ \\
\hline \multirow[t]{2}{*}{$A^{\prime}$} & - late diastolic myocardial relaxation velocity & LVMM & - left ventricular muscle mass \\
\hline & & LVWT & - left ventricular wall thickness \\
\hline $\mathrm{A}_{1}^{\prime}$ & $\begin{array}{l}\text { - late diastolic lateral myocardial relaxation } \\
\text { velocity determined by TDI }\end{array}$ & & $\begin{array}{l}\text { (interventricular septum thickness }+\mathrm{LV} \\
\text { posterior wall thickness) }\end{array}$ \\
\hline \multirow{2}{*}{$\mathrm{A}_{\mathrm{s}}^{\prime}$} & - late diastolic septal myocardial relaxation & MRI & - magnetic resonance imaging \\
\hline & velocity determined by TDI & MV & - mitral valve \\
\hline BM & - body mass index & $\mathrm{R}$ & - right ventricular or right ventricle \\
\hline & -00 & RVAd & - right ventricular diastolic area \\
\hline & & RVAs & - right ventricular systolic area \\
\hline & $\begin{array}{l}\text { - peak now velocity or the early pnase or } \\
\text { diastolic filling }\end{array}$ & RVFAC & - right ventricular fractional area change \\
\hline$E^{\prime}$ & - early diastolic myocardial relaxation & \multicolumn{2}{|c|}{$\begin{aligned} \text { RVLADd - } & \text { right ventricular long axis internal } \\
& \text { end-diastolic diameter }\end{aligned}$} \\
\hline $\mathrm{E}_{1}^{\prime}$ & - late diastolic lateral myocardial relaxation & \multicolumn{2}{|c|}{$\begin{array}{c}\text { RVSADd - right ventricular short axis internal } \\
\text { end-diastolic diameter }\end{array}$} \\
\hline \multirow[t]{2}{*}{$\mathrm{E}_{\mathrm{s}}^{\prime}$} & $\begin{array}{l}\text { velocity determined by TDI } \\
\text { - early diastolic septal myocardial relaxation }\end{array}$ & $\mathrm{S}^{\prime}$ & $\begin{array}{l}\text { - systolic myocardial velocity determined by } \\
\text { TDI }\end{array}$ \\
\hline & velocity determined by TDI & \multirow[t]{2}{*}{$\mathrm{S}_{1}$} & \multirow{2}{*}{$\begin{array}{l}\text { - systolic lateral myocardial velocity } \\
\text { determined by TDI }\end{array}$} \\
\hline HR & - heart rate & & \\
\hline LV & - left ventricular or left ventricle & \multirow{2}{*}{$\mathrm{S}_{\mathrm{s}}$} & \multirow{2}{*}{$\begin{array}{l}\text { - systolic septal myocardial velocity } \\
\text { determined by TDI }\end{array}$} \\
\hline LVIDd & - left ventricular internal end-diastolic & & \\
\hline & diameter & TAPSE & - Tricuspid Annular Plane Systolic Excursion \\
\hline \multirow{2}{*}{\multicolumn{2}{|c|}{$\begin{array}{l}\text { LVLADd - left ventricular long axis internal end- } \\
\text { diastolic diameter }\end{array}$}} & TDI & - Tissue Doppler Imaging \\
\hline & & TV & - tricuspid valve \\
\hline
\end{tabular}


The relationship of the Doppler assessed TV to MV E/A was similar in athletes and in non-athletes in the studies in which no difference was seen between athletic and non-athletic subjects $(8,21,23)$ or a higher E/A was found in older endurance athletes but not in strength athletes (5). Several authors found, however, little or no difference between athletes and nonathletes in TV E/A, while MV E/A was higher in athletes $(5,12,17)$.

From the TDI parameters $S$ ' indicates systolic function. In most of the studies no difference was found between different athletes and non-athletes $(6,8,12)$.

We found very few data in which the TDI measurements of the LV and RV have been compared, and in most of the studies, differences between athletes and non-athletes were found to be similar $(12,20,23)$.

The ratio of blood flow to tissue movement velocity $E / E^{\prime}$ is postulated to be an index of the ventricular filling characteristics. It has been very poorly investigated in the RV of the athletes; we found only one study dealing with this question (23), and no difference was seen between athletes and non-athletes.

The aim of the present study was to compare the morphologic and functional adaptation of the $\mathrm{V}$ and LV to regular physical activity by transthoracic echocardiography. To this end cardiac data were compared between athletes and non-athletes, differences in the LV and in the RV were compared with each other. Regarding that the LV E/A is highly dependent on HR (10); relationships between the transmitral or transtricuspid flow and HR were also investigated.

\section{Materials and Methods}

\section{Subjects}

Seventy-seven male volunteers (aged 18-40 years, Caucasian in origin) were recruited in accordance with the principles of the Helsinki Declaration. Based on their level of physical activity, the subjects were divided into two groups. The 52 athletes were international or national level competitors engaged in endurance sports: 31 triathletes, 12 kayaker-canoeists, 3 pentathletes, and two swimmers, cyclists and long distance runners each. Their training amount exceeded 10 hours per week, and their training history was greater than 6 years. No subjects were taking medicine. Non-athletes were young, inactive, normotensive, healthy men with no cardiovascular risk factors in their history; their weekly training hours did not exceed 3 hours, weekly training hours were highly greater in the athletes ( $18.9 \pm 6.7$ vs. $0.5 \pm$ $0.9, p<0.001)$.

Some basic data are presented in Table I, where some relative LV measures (rel.LVWT, rel.LVID, rel.LVMM) which have no equivalents in the RV are also indicated.

Before the investigations, each subject completed a medical sports questionnaire, which inquired into the subject's family history, cardiovascular risk factors and previous diseases, and in which the subject gave their written informed consent about the investigations. In each subject, a 12-lead ECG was made in recumbent position (Cardiosys H-01 ECG- Experimetria Ltd., Germany). Apart from some modifications acceptable in athletes (small extent T-wave inversion, incomplete right bundle branch block, early repolarisation) (4), no pathological alteration was detected. We must add that our subjects have participated in ECG and exercisetests for several years. 
Table I. Baseline characteristics and relative LV measures in athletes and non-athletes (mean \pm SD)

\begin{tabular}{|l|c|c|c|}
\hline & Athletes $(\boldsymbol{N}=\mathbf{5 2})$ & Non-athletes $(\boldsymbol{N}=\mathbf{2 5})$ & $\boldsymbol{p}$ value \\
\hline Age $(\mathrm{yr})$ & $24.6 \pm 5.1$ & $26.5 \pm 5.4$ & NS \\
\hline BSA $\left(\mathrm{m}^{2}\right)$ & $1.95 \pm 0.14$ & $1.96 \pm 0.18$ & NS \\
\hline BMI $\left(\mathrm{kg} / \mathrm{m}^{2}\right)$ & $22.9 \pm 2.4$ & $23.7 \pm 3.3$ & NS \\
\hline Heart rate $(\mathrm{bpm})$ & $54.8 \pm 9.3$ & $68.4 \pm 10.9$ & NS \\
\hline BPS $(\mathrm{mmHg})$ & $128.5 \pm 12.9$ & $126.6 \pm 10.1$ & NS \\
\hline BPD $(\mathrm{mmHg})$ & $77.9 \pm 9.5$ & $76.2 \pm 9.1$ & $<0.001$ \\
\hline rel.LVWT $(\mathrm{mm} / \mathrm{m})$ & $16.8 \pm 1.8$ & $14.6 \pm 1.7$ & $<0.05$ \\
\hline rel.LVID $(\mathrm{mm} / \mathrm{m})$ & $34.5 \pm 3.5$ & $32.7 \pm 3.6$ & $<0.001$ \\
\hline rel.LVMM $\left(\mathrm{g} / \mathrm{m}^{3}\right)$ & $99.4 \pm 17.3$ & $71.7 \pm 11.0$ & NS \\
\hline LV Fr.Sh. $(\%)$ & $34.1 \pm 4.4$ & $33.8 \pm 4.4$ & NS \\
\hline LV Ej. Fraction $(\%)$ & $71.0 \pm 5.8$ & $70.6 \pm 6.4$ & $<0.01$ \\
\hline LV rel. SV $\left(\mathrm{ml} / \mathrm{m}^{3}\right)$ & $36.6 \pm 8.9$ & $30.5 \pm 6.3$ & \\
\hline
\end{tabular}

BSA: body surface area; BMI: Body Mass Index; BPS: systolic blood pressure; BPD: diastolic blood pressure; rel.: relative, body-size-matched, LV: left ventricular, WT: wall thickness; ID: internal diameter; MM: muscle mass; Fr.Sh.: fractional shortening; Ej. Fraction: ejection fraction; SV: stroke volume; NS: No significant differences

\section{Echocardiographic measurements}

Investigations were performed in the Department of Health Sciences and Sports Medicine at the Faculty of Physical Education and Sports Sciences of the Semmelweis University from 2010 to 2013. Standardized echocardiographic measurements were made during the morning hours with a Philips HD15 type echocardiograph with a $2.5-3.5 \mathrm{MHz}$ transducer in a left lateral recumbent position with chest ECG control. The supervisor of this program was a cardiologist-specialist (T.K.). Two-dimensionally (2D)-guided M-mode, Doppler and tissue Doppler pictures were obtained. Longitudinal left and right internal end-diastolic and endsystolic diameters were obtained in apical four-chamber views (LVLADd, RVLADd). LV short axis diameters in end-systole and in end-diastole (LVIDd) were obtained in the parasternal view; RV short axis diameters (RVSADd) were detected in the apical fourchamber views. RVAd and RVAs were measured by outlining the endocardial borders of the $\mathrm{RV}$ in end-diastole and end-systole in the apical 4-chambers view. The RV fractional area change (RVFAC) was calculated according to the formula (RVAd - RVAs)/RVAd.

Mitral and tricuspid flow curves and peak velocities were measured by apical fourchamber view at the peak of the bicuspid and tricuspid valves. Early (E) and late (A) peak diastolic velocities were measured and their quotient $(\mathrm{E} / \mathrm{A})$ was calculated. TDI was used to determine maximal systolic (S'), early diastolic (E') and late diastolic (A') annular velocities both in the septal and in the lateral origin of the mitral and tricuspid valves. The ratio of the blood flow to tissue movement velocity (E/E') was also calculated. To avoid errors in the measurements, cardiac sizes were determined as the average values of 5-10 measurements; in the flow velocities, maximum values were taken into account.

In the normalization for body dimensions, BSA was used in keeping with the principle that the exponent of the numerator and denominator should be equal (15). The relative (rel.) formulas were as follows: 


$$
\begin{aligned}
& \text { rel.LVMM - LVMM/BSA } \\
& \text { rel.LVWT }- \text { LVWT/BSA } \\
& \text { rel.LVLADd }- \text { LVLADd } / \mathrm{BSA}^{1 / 2} \\
& \text { rel.LVIDd }- \text { LVIDd } / \mathrm{BSA}^{1 / 2} \\
& \text { rel.RVLADd }-\mathrm{RVLADd} / \mathrm{BSA}^{1 / 2} \\
& \text { rel.RVSADd }-\mathrm{RVSADd} / \mathrm{BSA}^{1 / 2}
\end{aligned}
$$

\section{Statistical analysis}

Differences between athletes and non-athletes were determined by the $t$-test for independent samples in StatSoft Statistica 10.0 program. Tables show mean and standard deviation (SD) values; significant differences were established at the level $p<0.05$. A relationship between $\mathrm{HR}$ and $\mathrm{E} / \mathrm{A}$ quotient indicating $\mathrm{LV}$ and RV diagnostic function was investigated by correlation analysis.

\section{Results}

No significant differences were found in age, BSA, BMI, systolic and diastolic blood pressure between the athletic and non-athletic groups; HR was significantly lower. LV morphological parameters which have no corresponding data from the RV are also indicated in Table I: rel LVWT, rel.LVID and rel.LVMM were significantly greater in athletes. There was no difference in the LV short axis fractional shortening and in the ejection fraction; relative stroke volume was enhanced in the athletes.

LV morphological and functional parameters are demonstrated in Table II. Rel. diastolic LV long axis diameter was significantly greater in the athletes. LV fractional shortening was not different between the athletes and non-athletes. In the transmitral flow velocities, the $\mathrm{E}$ was a little, non-significantly higher, the A was lower, therefore, the E/A was significantly higher in the athletes than in non-athletes.

From the LV TDI measurements the systolic velocities were similar in the septal region ( $\mathrm{S}$ 's), but in the lateral region $\left(\mathrm{S}_{1}\right)$ it was elevated in the athletes. E' amplitudes did not differ significantly in the septal region, but they were significantly higher in the athletes in the lateral region. The A' waves were lower in the septal region; E'/A' quotients were significantly higher in athletes, both at the septal and the lateral side. In terms of the E/E' ratio, the difference between the athletic and non-athletic groups was not significant at the septal wall, but at the lateral wall the ratio was significantly lower for the athletic group.

Data referring to the RV are indicated in Table III. Significant differences were seen in all of the RV dimensions; long and short axis diameters and diastolic areas were markedly larger in athletes than in non-athletes. The fractional shortening both in the short and long axis and the RV area change were similar for the two groups. There was not significant difference in the transtricuspid E, A and E/A values, and no significant difference was seen in the TDI values either. The only significant difference between the two groups was found in the TAPSE; the athletes showed higher values.

Relationships between transmitral and transtricuspid E/A quotients and HR are demonstrated in Figures 1 and 2 by scatter plot graphs. A significant negative correlation $(r=$ $-0.465)$ was found between the transmitral E/A and the HR, but no significant relationship was found between the tricuspid E/A and HR $(r=-0.004)$. 
Table II. Left ventricular dimensions and functions in athletes and non-athletes (mean \pm SD)

\begin{tabular}{|c|c|c|c|}
\hline & Athletes $(N=52)$ & Non-athletes $(N=25)$ & $p$ value \\
\hline rel.LVLADd (mm/m) & $63.8 \pm 5.6$ & $60.7 \pm 6.6$ & $<0.05$ \\
\hline LVLA.Fr.Sh. (\%) & $20.6 \pm 6.54$ & $22.1 \pm 6.86$ & NS \\
\hline rel.LVSADd $(\mathrm{mm} / \mathrm{m})$ & $37.8 \pm 3.1$ & $35.3 \pm 2.4$ & NS \\
\hline $\mathrm{E}(\mathrm{m} / \mathrm{s})$ & $0.91 \pm 0.17$ & $0.86 \pm 0.16$ & NS \\
\hline $\mathrm{A}(\mathrm{m} / \mathrm{s})$ & $0.46 \pm 0.11$ & $0.51 \pm 0.12$ & NS \\
\hline E/A ratio & $2.07 \pm 0.51$ & $1.75 \pm 0.36$ & $<0.01$ \\
\hline $\mathrm{S}_{\mathrm{s}}(\mathrm{m} / \mathrm{s})$ & $0.085 \pm 0.017$ & $0.086 \pm 0.014$ & NS \\
\hline$E_{s}^{\prime}(m / s)$ & $0.128 \pm 0.021$ & $0.134 \pm 0.022$ & NS \\
\hline $\mathrm{A}_{\mathrm{s}}^{\prime}(\mathrm{m} / \mathrm{s})$ & $0.071 \pm 0.016$ & $0.088 \pm 0.020$ & $<0.001$ \\
\hline $\mathrm{E}_{\mathrm{s}}^{\prime} / \mathrm{A}_{\mathrm{s}}^{\prime}$ ratio & $1.89 \pm 0.55$ & $1.62 \pm 0.55$ & $<0.05$ \\
\hline $\mathrm{E} / \mathrm{E}_{\mathrm{s}}^{\prime}$ ratio & $7.19 \pm 1.46$ & $6.56 \pm 1.38$ & NS \\
\hline $\mathrm{S}_{1}^{\prime}(\mathrm{m} / \mathrm{s})$ & $0.111 \pm 0.033$ & $0.095 \pm 0.027$ & $<0.05$ \\
\hline$E_{1}^{\prime}(m / s)$ & $0.19 \pm 0.050$ & $0.16 \pm 0.047$ & $<0.05$ \\
\hline $\mathrm{A}_{1}^{\prime}(\mathrm{m} / \mathrm{s})$ & $0.076 \pm 0.016$ & $0.078 \pm 0.018$ & NS \\
\hline $\mathrm{E}_{1}^{\prime} / \mathrm{A}_{1}^{\prime}$ ratio & $2.62 \pm 0.72$ & $2.18 \pm 0.87$ & $<0.001$ \\
\hline $\mathrm{E} / \mathrm{E}_{1}{ }_{1}$ ratio & $5.14 \pm 1.13$ & $6.11 \pm 4.74$ & $<0.05$ \\
\hline
\end{tabular}

rel.: relative, LV: left ventricular, LADd: long axis diameter in diastole; Fr.Sh.: fractional shortening; SADd: short axis diameter in diastole; E: peak flow velocity of the early phase of diastolic filling; A: peak flow velocity of the late (atrial) phase of diastolic filling; $\mathrm{S}_{\mathrm{s}}$ : systolic velocity of the septal wall, E' ${ }_{\mathrm{S}}$ : early diastolic septal myocardial relaxation velocity; $\mathrm{A}_{\mathrm{s}}$ : late diastolic septal myocardial relaxation velocity; $\mathrm{S}_{1}{ }_{1}$ : systolic velocity of the lateral wall; $\mathrm{E}_{1}^{\prime}$ : early diastolic lateral relaxation velocity; $\mathrm{A}_{1}^{\prime}$ : late diastolic lateral relaxation velocity; NS: no significant differences

Table III. Right ventricular dimensions and function in athletes and non-athletes (mean $\pm \mathrm{SD})$

\begin{tabular}{|c|c|c|c|}
\hline & Athletes $(N=52)$ & Non-athletes $(N=25)$ & $p$ value \\
\hline rel.RVLADd (mm/m) & $63.4 \pm 6.3$ & $56.4 \pm 6.3$ & $<0.001$ \\
\hline RVLA.Fr.Sh. (\%) & $25.9 \pm 6.3$ & $27.9 \pm 7.9$ & NS \\
\hline rel.RVSADd $(\mathrm{mm} / \mathrm{m})$ & $27.3 \pm 3.6$ & $23.6 \pm 2.7$ & $<0.001$ \\
\hline RVSA.Fr.Sh. (\%) & $20.3 \pm 8.4$ & $19.8 \pm 10.9$ & NS \\
\hline RVAd $\left(\mathrm{cm}^{2}\right)$ & $28.0 \pm 5.0$ & $21.3 \pm 4.3$ & $<0.001$ \\
\hline RVFAC (\%) & $42.7 \pm 6.8$ & $44.0 \pm 6.5$ & NS \\
\hline TAPSE (mm) & $29.3 \pm 4.9$ & $25.8 \pm 3.9$ & $<0.01$ \\
\hline $\mathrm{E}(\mathrm{m} / \mathrm{s})$ & $0.63 \pm 0.15$ & $0.58 \pm 0.12$ & NS \\
\hline $\mathrm{A}(\mathrm{m} / \mathrm{s})$ & $0.33 \pm 0.10$ & $0.30 \pm 0.067$ & NS \\
\hline $\mathrm{E} / \mathrm{A}$ ratio & $2.02 \pm 0.53$ & $1.98 \pm 0.50$ & NS \\
\hline $\mathrm{S}_{\mathrm{s}}{ }^{\prime}(\mathrm{m} / \mathrm{s})$ & $0.092 \pm 0.023$ & $0.089 \pm 0.013$ & NS \\
\hline$E_{s}^{\prime}(m / s)$ & $0.132 \pm 0.028$ & $0.130 \pm 0.025$ & NS \\
\hline $\mathrm{A}_{\mathrm{s}}^{\prime}(\mathrm{m} / \mathrm{s})$ & $0.073 \pm 0.020$ & $0.078 \pm 0.016$ & NS \\
\hline $\mathrm{E}_{\mathrm{s}}^{\prime} / \mathrm{A}_{\mathrm{s}}^{\prime}$ ratio & $1.89 \pm 0.49$ & $1.72 \pm 0.45$ & NS \\
\hline $\mathrm{E} / \mathrm{E}_{\mathrm{s}}{ }_{\mathrm{s}}$ & $4.99 \pm 1.37$ & $4.39 \pm 1.19$ & $\mathrm{NS}$ \\
\hline $\mathrm{S}_{1}^{\prime}(\mathrm{m} / \mathrm{s})$ & $0.128 \pm 0.032$ & $0.133 \pm 0.023$ & NS \\
\hline
\end{tabular}


Table III (continued)

\begin{tabular}{|l|c|c|c|}
\hline & Athletes $(\boldsymbol{N}=\mathbf{5 2})$ & Non-athletes $(\boldsymbol{N}=\mathbf{2 5})$ & $\boldsymbol{p}$ value \\
\hline $\mathrm{E}_{1}^{\prime}(\mathrm{m} / \mathrm{s})$ & $0.150 \pm 0.031$ & $0.145 \pm 0.028$ & NS \\
\hline $\mathrm{A}_{1}^{\prime}(\mathrm{m} / \mathrm{s})$ & $0.105 \pm 0.032$ & $0.110 \pm 0.029$ & NS \\
\hline $\mathrm{E}_{1}^{\prime} / \mathrm{A}_{1}^{\prime}$ ratio & $1.56 \pm 0.58$ & $1.45 \pm 0.59$ & NS \\
\hline $\mathrm{E}^{\prime} \mathrm{E}_{1}{ }_{1}$ & $4.19 \pm 1.11$ & $4.00 \pm 1.07$ & NS \\
\hline
\end{tabular}

RV: right ventricular, LAd: long axis internal end-diastolic diameter; Fr.Sh.: fractional shortening;

SADd: short axis diameter in end-diastole; SA.Fr.Sh.: short axis fractional shortening; Ad: diastolic area;

TAPSE: tricuspid annular plane systolic excursion; E: peak flow velocitiy of the early phase of diastolic filling; A: peak flow velocity of the late (atrial) phase of diastolic filling; $\mathrm{S}_{\mathrm{s}}{ }_{\mathrm{s}}$ : systolic annular velocity, $\mathrm{E}_{\mathrm{s}}{ }_{\mathrm{s}}$ : early diastolic septal myocardial relaxation velocity; $\mathrm{A}_{\mathrm{s}}$ : late diastolic septal myocardial relaxation velocity; $\mathrm{E}_{\mathrm{s}}$ : early diastolic septal myocardial relaxation velocity; $\mathrm{S}_{1}{ }_{1}$ : systolic velocity of the lateral wall; $\mathrm{E}_{1}$ : early diastolic lateral relaxation velocity; $\mathrm{A}_{1}^{\prime}$ : late diastolic lateral relaxation velocity; NS: no significant differences

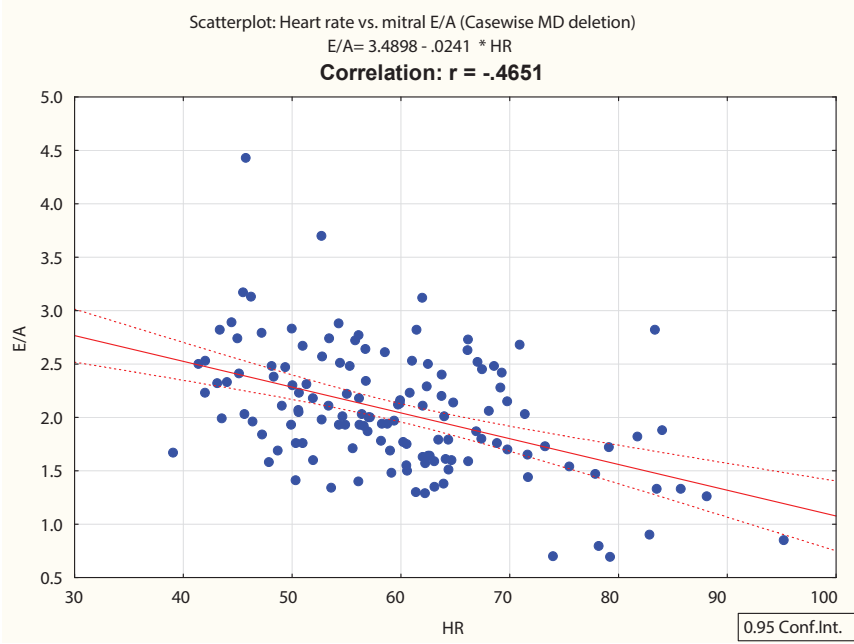

Fig. 1. Correlation between heart rate and mitral E/A quotient

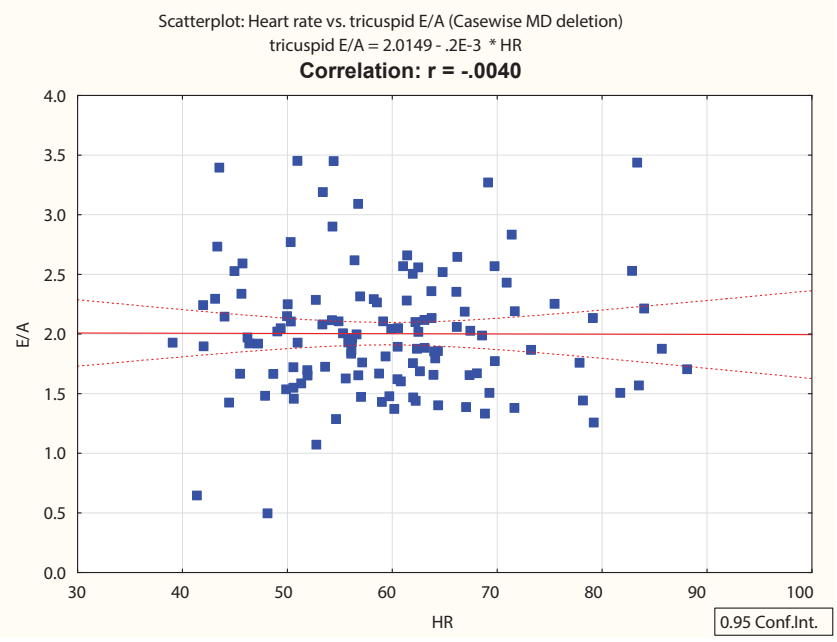

Fig. 1. Correlation between the heart rate and mitral E/A quotient
Fig. 2. Correlation between the heart rate and tricuspid E/A quotient 


\section{Discussion}

In the present study, the morphologic and functional adaptation of the RV and the LV was investigated in top-level male endurance athletes and age- and body-size-matched sedentary subjects. Characteristics of the athlete's heart were unambiguously indicated by the lower HR and the higher rel.LVWT, rel.LVID and rel.LVMM.

If we liked to compare RV and LV adaptation, parameters detectable in both ventricles should be investigated in the two groups. As a morphological parameter, such a measure is the relative long axis diameter; among the functional parameters such data are the long-axis shortening fractions, transmitral and transtricuspid flow velocities, E, A and their ratio, the E/A and the TDI data, E', A', S' and E'/A' in the septal and lateral walls of the two ventricles.

\section{Morphology}

As comparable morphologic parameters, rel.LVLADd $(\mathrm{mm} / \mathrm{m})$ and rel.LVSADd $(\mathrm{mm} / \mathrm{m})$ in the LV, rel.RVLADd $(\mathrm{mm} / \mathrm{m})$, rel.RVSADd $(\mathrm{mm} / \mathrm{m})$ and RVAd $\left(\mathrm{cm}^{2}\right)$ in the RV were taken into consideration. The extents of differences between the athletes and non-athletes in the LV and RV were compared.

Our results were similar to those according to which ventricular enlargements in endurance athletes are nearly similar on the two sides $(3,5,6,17,22)$ or slightly stronger on the right side $(11,23,24)$. In the relative longitudinal diameters, athletes showed a slightly greater increase in the $\mathrm{RV}(12.4 \%, p<0.001)$ than the $\mathrm{LV}(7.1 \%, p<0.05)$. The LV short axis diameter was measured in the parasternal view; in the athletes it was not larger. RV short axis diameter was detected in the apical view, and the difference was $15.7 \%(p<0.001)$. Our results and the data of other authors suggest a proportional increase in the two ventricles, but a greater increase in the RV cannot be excluded. A disproportionally large intensity effort may induce an even more marked remodelling in the RV than in the $\operatorname{LV}(11,23,24)$, the cause of which could be that during a physical load the resistance in pulmonary circulation is much higher than in systemic circulation, and therefore, the pressure and the workload of the RV is more extensive $(7,11)$.

\section{Systolic functions}

In our study, similar systolic diminishing of all of these indicators was seen in the athletes and non-athletes in the two chambers: LV short axis and long axis fractional shortening, LV ejection fraction, RV short and long axis fractional shortening and RVFAC. Regarding the hypertrophy of both ventricles, this should mean a slightly larger stroke volume, which with the lower HR provides a similar cardiac output.

Our data correspond to the data of other authors. In most of the publications, LV shortening fraction or ejection fraction does not differ profoundly between the athletes and non-athletes $(3,15,19)$. Similarly, in several studies, no differences were seen between the athletes and non-athletes in the RVFAC (6). If there were any, smaller RV changes seemed to be in athletes than in non-athletes: La Gerche et al. (11) and Teske et al. (23) found smaller RV ejection fraction in endurance athletes; Poh et al. (20) found a smaller RVFAC in elite speed-skaters than in non-athletes.

Taken together, in the RV systolic changes either there is no difference between the athletes or non-athletes, or changes in the athletes are slightly smaller, while no such trend occurs in the LV. It is not excluded that the slightly larger relative RV volume with the same and/or lower ejection fraction can produce a similar stroke volume.

Systolic function is thought to be characterised by the TDI determined S' $(5,14,15)$. In our present study, no significant difference was seen in the RV S'. In other studies, higher 
values were seen in older (47-48 years) strength and endurance athletes (5) or in sprint athletes, namely in speed skaters (20). It seems that if there is any effect of regular training on the RV S', it is on athletes in strength and speed sports and not in endurance athletes.

Tricuspid Annular Plane Systolic Excursion (TAPSE) was higher in the athletes than in the non-athletes. Our data are in accordance with those of other authors who also found higher values in endurance athletes (24), while D'Andrea et al. (6) found no differences between the values of strength and endurance athletes and non-athletes.

LV stroke volume can be estimated by echocardiography as the difference between diastolic and systolic LV volume; it is rather difficult to determine the RV stroke volume. Similarly to the LV, it should be higher in athletes to perform at a similar cardiac output despite the lower HR. Increased RV shortening fractions and TAPSE can be signals of this elevated RV stroke volume.

\section{Diastolic function}

In our results, a definite difference was seen between the training effects on the LV and RV: differences were seen in the LV (higher E/A, E' ${ }_{s} / A_{s}^{\prime}, E_{1}^{\prime} / A_{1}^{\prime}$ and lower $E_{1} / E_{1}^{\prime}$ in the athletes than in the non-athletes), while no differences were seen in the RV.

The results are in accordance with most of the data of other authors, showing that blood flow and TDI indicated diastolic functions are more indicative in the LV than in the RV.

$\mathrm{LV} \mathrm{E} / \mathrm{A}$ is often reported to be higher in athletes, especially in endurance-trained and in older males $(5,15,19)$; according to some data there is a significant difference in the LV E/A, but no difference in the RV $(8,17)$. There are reports, however, in which similar results were seen in the LV and RV: increased quotients in both chambers (6) or no significant difference was seen either in the RV or in the $\operatorname{LV}$ E/A $(21,22)$.

Most of the data obtained by TDI $(8,20,24)$ indicate no differences in the RV E' and A' and the E'/A' between athletes and non-athletes. D'Andrea et al. (5) published some data according to which the E'/A' ratio was markedly higher in both power and endurance athletes than in passive persons, but these data were observed in older (age: 47 years) athletes.

Our results, together with results of other authors $(7,12,15,19)$, indicate that RV lusitropic and TDI indices are not markedly different in athletic subjects as compared with those of non-athletes, while in the LV parameters athletes show higher values.

The higher LV E/A and E'/A' of the athletes can be explained by several factors, for example, better compliance, lower HR, or other factors. An exact clarification of the causes of the difference between the behaviour in LV and RV requires further studies.

A possible cause can be the different behaviour of the two chambers during endurance loading, arising from the difference between the total peripheral resistance and pulmonary resistance $(7,11)$ : after an acute extensive endurance $\mathrm{RV}$ E/A decreased, LV E/A did not change.

As regards HR, we made a comparison between LV and RV E/A and HR; in the LV, a highly significant negative correlation was found, while in the RV, no significant correlation was observed. This difference can contribute to the smaller effect of regular training on the RV than on the LV.

It should be emphasised that in the general medical praxis ventricular hypertrophy is accompanied by an impaired diastolic function not only in the LV, but also in the RV, for example, in obesity, hypertrophic cardiomyopathy or in diabetes $(9,23)$. The non-impaired diastolic function against the RV hypertrophy indicates the physiologic character of RV hypertrophy in the athletes. 


\section{Conclusion}

In summarising our results and the data of others, it seems that endurance athletes' adaptation to regular physical exercise is nearly similar in the two ventricles. A slightly stronger morphological and poorer functional adaptation can be postulated in the RV than in the LV in the athletes, the cause of which can be that during physical load the resistance in pulmonary circulation is much higher than in systemic circulation, and therefore, the pressure and the workload of the RV is more extensive. It is possible that the higher morphologic adaptation offers a sufficient increase in the function, and further functional adaptation is not necessary.

\section{REFERENCES}

1. Apor A, Merkely B, Morrell T, Zhu S, Ghosh E, Vágó H, Andrássy P, Kovács SJ: Diastolic function in Olympic athletes versus controls: Stiffness-based and relaxation-based echocardiographic comparisons. J. Exerc. Sci. Fitness. 11, 29-34 (2013)

2. Baggish AL, Wang F, Weiner RB, Elinoff JM, Tournoux F, Boland A, Picard MH, Hutter AM jr, Wood MJ: Training-specific changes in cardiac structure and function: a prospective and longitudinal assessment of competitive athletes. J. Appl. Physiol. 104, 1121-1128 (2008)

3. Baggish AL, Wood MJ: Athlete's heart and cardiovascular care of the athlete. Scientific and clinical update. Circulation 123, 2723-2735 (2011)

4. Corrado D, Pelliccia A, Heidbuchel H, Sharma S, Link M, Basso C, Biffi A, Buja G, Delise P, Gussac I, Anastasakis A, Bojesson M, Bjørnstad HH, Carrè F, Deligiannis A, Duqmore D, Fagard R, Hoogsteen J, Mellwiq KP, Panhyzen-Goedkoop N, Solberg E, Vanhees L, Dezner J, Estes NA $3^{\text {rd }}$, Illiceto S, Maron BJ, Peidro R, Schwartz PJ, Stein R, Thiene G, Zeppilli P, McKenna WJ: Recommendations for interpretation of 12-lead electrocardiogram in the athletes. Eur. Heart J. 31, 243-259 (2010)

5. D’Andrea A, Caso P, Scarafile R, Salerno G, De Corato G, Mita C, Di Salvo G, Allocca F, Colonna D, Caprile M, Ascione L, Cuomo S, Calabrỏ R: Biventricular myocardial adaptation to different training protocols in competitive master athletes. Int. J. Cardiol. 115, 342-349 (2007)

6. D’Andrea A, Riegler L, Golia E, Cocchia R, Scarafile R, Salerno G, Pezzullo E, Nunziata L, Citro R, Cuomo S, Caso P, Di Salvo G, Cittadini A, Russo MG, Calabró R, Bossone E: Range of right heart measurements in toplevel athletes: The training impact. Int. J. Cardiol. 164, 48-57 (2013)

7. Douglas PS, O'Toole ML, Hiller WDB, Reichek N: Different effects of prolonged exercise on the right and left ventricles. JACC. 15, 64-69 (1990)

8. Erol MK, Karakalleoglu S: Assessment of right heart function in the athlete's heart. Heart Vessels 16 (5), 175180 (2002)

9. Haddad F, Sharon AH, Rosenthal DN, Murphy DJ: Right ventricular function in cardiovascular disease, Part 1. Anatomy, physiology, aging, and functional assessment of the right ventricle. Circulation 117, 1436-1448 (2008)

10. Kneffel Zs, Varga-Pintér B, Tóth M, Major Zs, Pavlik G: Relationship between the heart rate and E/A ratio in athletic and non-athletic males. Acta Physiol. Hung. 98, 284-294 (2011)

11. La Gerche A, Heidbüchel H, Burns AT, Mooney DJ, Taylor AJ, Pfluger HB, Inder WJ, MacIsaac AT, Prior DL: Disproportionate exercise load and remodelling of the athlete's right ventricle. Med. Sci. Sports Exer. 43, 974-981 (2011)

12. Moro AS, Okoshi MP, Padovani CP, Okoshi K: Doppler echocardiography in athletes from different sports. Med. Sci. Monit. 19, 187-193 (2013)

13. Oxborough D, Sharma S, Shave R, Whyte G, Birch K, Artis N, Batterham AM, George K: The right ventricle of the endurance athlete: the relationship between morphology and deformation. J. Am. Soc. Echocardiogr. 25 (3), 263-271 (2012)

14. Pavlik G, Major Zs, Csajági E, Jeserich M, Kneffel Zs: The athlete's heart. Part II. Influencing factors on the athlete's heart: types of sports and age. Acta Physiol. Hung. 100, 1-27 (2013)

15. Pavlik G, Major Zs, Varga-Pintér B, Jeserich M, Kneffel Zs: The athlete's heart. Part I. Acta Physiol. Hung. 97, 337-353 (2010)

16. Pelliccia A, Maron BJ, Spataro A, Proschan MA, Spirito P: The upper limit of physiologic cardiac hypertrophy in highly trained elite athletes. N. Engl. J. Med. 34, 295-301 (1991) 
17. Perseghin G, De Cobelli F, Esposito A, Lattuada G, Terruzzi I, La Torre A, Belloni E, Canu T, Scifo P, Del Maschio A, Luzi L, Alberti G: Effect of the sporting discipline on the right and left ventricular morphology and function of elite male track runners: A magnetic resonance imaging and phosphorus 31 spectroscopy study. Am. Heart J. 154, 937-942 (2007)

18. Petersen SE, Hudsmith LE, Robson MD, Doll HA, Francis JM, Wiesmann F, Jung BA, Hennig J, Watkins H, Neubauer S: Sex-specific characteristics of cardiac function, geometry, and mass in young adult elite athletes. J. Magn. Res. 24, 297-303 (2006)

19. Pluim BM, Zwinderman AH, Van Der Laarse A, Van Der Wall EE: The athlete's heart: a meta analysis of cardiac structure and function. Circulation 101, 336-344 (2000)

20. Poh KK, Ton-Nu TT, Neilan TG, Tournoux FB, Picard MH, Wood MJ: Myocardial adaptation and efficiency in response to intensive physical training in elite speedskaters. Int. J. Cardiol. 126, 346-351 (2008)

21. Prakken NH, Velthuis BK, Bosker AC, Mosterd A, Teske AJ, Mali WP, Cramer MJ: Relationship of ventricular and atrial dilatation to valvular function in endurance athletes. Br. J. Sports Med. 45, 178-184 (2011)

22. Scharhag J, Schneider G, Urhausen A, Rochette V, Kramann B, Kindermann W: Athlete's heart: right and left ventricular mass and function in male endurance athletes and untrained individuals determined by magnetic resonance imaging. J. Am. Coll. Cardiol. 40, 1856-1863 (2002)

23. Teske AJ, Prakken NH, De Boeck BW, Velthuis BK, Martens EP, Doevendans PA, Cramer MJ: Echocardiographic tissue deformation imaging of right ventricular systolic function in endurance athletes. Eur. Heart J. 30, 969-977 (2009)

24. Teske AJ, Prakken NH, De Boeck BWL, Velthuis BK, Doevendans PA, Cramer MJM: Effect of long term and intensive endurance training in athletes on the age related decline in left and right ventricular diastolic function as assessed by Doppler echocardiography. Am. J. Cardiol. 104, 1145-1151 (2009) 